\title{
Self-isolation negatively impacts self-management of diabetes during the coronavirus (COVID-19) pandemic
}

\author{
Shahina Pardhan ${ }^{1 *} \mathbb{B}$, Md. Saiful Islam², Guillermo F. López-Sánchez ${ }^{1}$, Tirthalal Upadhyaya ${ }^{3}$ and Raju P. Sapkota
}

\begin{abstract}
Background/Aim: People with diabetes are at a greater risk of serious complications from Coronavirus disease (COVID-19). Self-management of diabetes is therefore of paramount importance. The purpose of this study is to compare self-management of diabetes pre-COVID-19 and during the COVID-19 pandemic.

Methods: 679 participants with diabetes completed an online structured questionnaire survey. Various exposure variables (demographics, duration, treatment and complications of diabetes, self-isolation, etc.) were analysed to examine associations with the following outcome variables: (i) fluctuation of blood glucose levels, (ii) access to diabetes medicine, (iii) access to healthy diet, (iv) physical activity. Adjusted multiple regression analysis ascertained significant associations for each outcome variable against exposure variables.

Results: Multiple regression analysis showed that self-isolation was significantly associated with greater fluctuation in blood glucose levels $(O R=1.8,95 \% \mathrm{Cl}=1.2-2.6, p=0.005)$, reduced access to diabetes medicine $(O R=1.9$, $95 \% \mathrm{Cl}=1.1-3.1, p=0.02)$ and reduced access to healthy $\operatorname{diet}(\mathrm{OR}=3.0,95 \% \mathrm{Cl}=2.0-4.6, p<0.001)$. Fluctuation in blood glucose level was also significantly associated with having at least one complication of diabetes $(O R=2.2,95 \%$ $C l=1.2-3.9, p=0.008)$ and reduced access to diabetes medicine was significantly higher in people who were on insulin $(O R=2.1,95 \% C l=1.3-3.3, p=0.001)$.

Conclusions: Self-isolation was shown to impact almost all factors that influence self-management of diabetes. A targeted approach to improved access to diabetes medicine, healthy diet for people who needed to self-isolate is vital in order to ensure that they are able to self-manage their diabetes effectively.
\end{abstract}

Keywords: Diabetes, Self-management, Blood glucose, COVID-19, Mandatory self-isolation

\section{Introduction}

Since the coronavirus disease was first identified in Wuhan, Hubei province of China in 2019 (named as COVID-19 by the World Health Organisation [WHO], on 11 February 2020), its spread around the world at an alarming rate forced the WHO to declare it as a global health emergency in just within two and half months

*Correspondence: shahina.pardhan@anglia.ac.uk

${ }^{1}$ Vision and Eye Research Institute, School of Medicine, Anglia Ruskin University, East Road, Cambridge CB1 1PT, UK

Full list of author information is available at the end of the article (on March 11, 2020) from its first detection. So far (as of September 29, 2021), more than 232 million people have been infected by COVID-19 worldwide with over 4.7 million mortalities [1].

The pandemic has affected the lives and livelihood of millions of people forcing them to suddenly adapt to a 'new normal' way of living. Amongst the changes brought about by the COVID-19 pandemic include the requirement to wear facemasks, frequent washing of hands, the need to maintain safe physical distance from each other, having to minimise non-essential travel/contact, etc. Furthermore, people have been forced to live under severe original author(s) and the source, provide a link to the Creative Commons licence, and indicate if changes were made. The images or other third party material in this article are included in the article's Creative Commons licence, unless indicated otherwise in a credit line to the material. If material is not included in the article's Creative Commons licence and your intended use is not permitted by statutory regulation or exceeds the permitted use, you will need to obtain permission directly from the copyright holder. To view a copy of this licence, visit http://creativecommons.org/licenses/by/4.0/. The Creative Commons Public Domain Dedication waiver (http://creativeco mmons.org/publicdomain/zero/1.0/) applies to the data made available in this article, unless otherwise stated in a credit line to the data. 
restrictions in movement and ban on the social gathering, closure of shops, sporting venues, leisure parks and praying venues, shortage of food supplies and panic buying. The pandemic also has a negative impact on the mental wellness of people as a result of worry around fear of job losses, the possibility of being infected with coronavirus, etc. Changes due to pandemic also included having to work remotely and an increased sedentary lifestyle. In addition, self-isolation is a requirement if infected with COVID-19 or someone living with has tested positive for COVID-19. All these changes can impact upon people's access to medicine, physical activity, healthy diet and health services including cancellation or postponement of non-urgent appointments [2], leading to poor control of non-communicable disease including diabetes [3-9].

People with underlying diseases such as diabetes are at an increased risk of severe illness and mortality from the COVID-19 infection. A recent meta-analysis of 33 studies found that people with diabetes were 2.7 times more likely to develop severe illness following COVID19 infection and 1.9 times more likely to die from it compared to those without diabetes [10]. It is therefore important that people with diabetes are able to monitor blood glucose levels regularly, attend doctor/hospital appointments, access the right kind of medicine, be physically active and eat healthy food [11]. Research also suggests that active and proper self-management reduces the risk of serious complications of diabetes by $53-63 \%$ and the risk of mortality by $46 \%[12,13]$ as people selfmanage their diabetes over $95 \%$ of the time [14].

Recent research on people with diabetes has shown increased consumption of carbohydrate and sugary foods, decreased physical activity, reduced self-monitoring of blood glucose levels and increased stress and anxiety during the pandemic [15-19]. On comparing pre-pandemic and during pandemic states, studies have shown greater fluctuation in blood glucose levels in patients with diabetes [20], worsening of complications of diabetes [21] and higher blood glucose levels in newly diagnosed patients [22]; factors associated with these changes are not well understood. On the other hand, studies from India and Poland have reported a positive effect on people's behaviour and blood glucose levels during the pandemic including more consumption of fruits, vegetables and nutritious/regular meals $[15,23]$. A study from Italy reported that blood glucose levels improved during the first seven days of stopping to work suggesting that slowing down of daily routine might have a beneficial effect (at least in the short-term) on diabetes control [24].

A number of studies have examined the effect of COVID lockdown on diabetes self-management [25-28].
These studies found that blood glucose levels fluctuated more during the COVID lockdown and were associated with poor diet, increased anxiety and reduced physical activity levels. Various interventions were suggested such as increased physical activity at home $[27,28]$ and eating more vegetables [27] to improve blood glucose levels during the lockdown. However, how different factors including (but not limited to) the mandatory need to self-isolate (with strict domiciliary confinements) because someone (or a person living with) was infected with COVID-19, duration of self-isolation, age, gender, duration, treatment and complications of diabetes are associated with diabetes self-management during the COVID pandemic is not well known. Needing to self-isolate means people are strictly not able to go out of their homes, as a consequence of which their basic outdoor activities such as walking, running, cycling, going to the doctor/pharmacy to get medicine and buying healthy foods are likely to get worsened compared to those who did not need to selfisolate as they could still go out of their homes for these basic outdoor activities. These (above) factors, together with anxiety about underlying health (e.g., diabetes) and loneliness because of not being able to socialise faceto-face with friends and relatives may put people with diabetes who needed to self-isolate mandatorily (due to COVID-19 infection or coming in close contact with someone who was infected with COVID-19) at a higher risk of poor diabetes self-management and uncontrolled diabetes, which was investigated in this study. Such as investigation is needed in order that evidence-led guideline development for improved diabetes self-management by targeting those risk factors significantly associated with poor diabetes self-management during (or specific to) the COVID-19 pandemic is possible.

\section{Methodology \\ Study aim}

To examine how various exposure factors including demographic characteristics (age, gender), duration, treatment and complications of diabetes, the need to self-isolate (due to being infected or coming in contact with someone infected with COVID-19) and duration of self-isolation (see Table 1), were associated with the following outcomes of diabetes self-management: (i) fluctuation of blood glucose levels; (ii) reduced access to diabetes medicine; (iii) reduced access to right kind of food for diabetes; and (iv) reduced physical activity.

\section{Study design and setting}

A cross-sectional online survey carried out between May 2020 and November 2020. 
Table 1 Demographics with participant numbers and percentages for different exposure variables

\begin{tabular}{llc}
\hline Variable & Categories & Number (\%) \\
\hline Age group & $<50$ years & $265(39 \%)$ \\
& $414(61 \%)$ & $354(52.1 \%)$ \\
Gender & 50 years or above & $325(47.9 \%)$ \\
& Male & $294(43.3 \%)$ \\
Duration of diabetes & Female & $385(56.7 \%)$ \\
& Up to 5 years & $58(8.6 \%)$ \\
Having diabetes complications like retinopathy & $>5$ years & $617(91.4 \%)$ \\
& Yes & $204(30.4 \%)$ \\
Diabetic Treatment & No & $466(69.6 \%)$ \\
& Insulin/combined & $140(20.6 \%)$ \\
Needing to self-isolate mandatorily & Non-insulin & Yes \\
Duration of self-isolation & No/prefer not say & $539(79.4 \%)$ \\
& Up to one week & $53(37.9)$ \\
Tested positive for COVID-19 by a standard test & Over one week & $82(62.1 \%)$ \\
& Yes & $55(17.1 \%)$ \\
\hline
\end{tabular}

\section{Survey material}

A structured questionnaire built on an existing validated diabetes self-management questionnaire [29], and previous literature on factors that may affect the management of diabetes including demographics, history of diabetes (duration/treatment and any long-term complications such as retinopathy, neuropathy, nephropathy), access to diabetes medicine, fluctuation in blood glucose levels, access to a healthy diet, and physical activity $[8,9]$. Questions around COVID-19 such as whether participants had experienced symptoms or tested positive for COVID-19 by a standard Polymerase Chain Reaction (PCR) test, whether they needed to self-isolate, etc., were adapted from the previous studies [30, 31]. All questions were reviewed and agreed upon by authors (SP and RS) who are experienced in conducting survey-based studies $[8,9,30]$, which were then pretested/validated on a small sample of people with diabetes $(n=20)$ who were not included in this study.

\section{Power analysis}

With a $12 \%$ prevalence rate of diabetes in the adult population [31], precision error of $5 \%$ and type $1(\alpha)$ error of $5 \%$, the required sample size was calculated to be 676 . Our sample size exceeds this number.

\section{Study participants}

A total of 679 participants (UK, Bangladesh, India and Nepal, $52 \%$ male) above 18 years of age (median age range: 50-60 years) who self-reported to have diabetes (of any type) completed the survey. Work from our laboratory has shown that not all our participants are aware of the type of diabetes they have [9] so we asked them to comment on whether they were on insulin treatment or not which we consider to be more appropriate for the aims of this study (30.4\% of the total participants reported being on insulin or combined treatment, Table 1). Also, we did not ask for information about gestational diabetes or maturity onset diabetes of the young (MODY), which is caused by a gene mutation.

Participants were treated in accordance with applicable ethical guidelines that followed the tenets of the Helsinki Declaration. Information that could identify individual participant during or after data collection were not recorded. The study protocol was approved by Anglia Ruskin University's Faculty of Health, Education, Medicine and Social Care Research Ethics Panel [ref. no.: 19/20/024].

\section{Procedure}

Participants were invited to take part in the study through social media (Facebook, WhatsApp), online adverts, word of mouth, or contacts through acquaintances. Participants were informed at the beginning (i.e., before the survey began) about the purpose of the study and were provided with information about their anonymity and confidentiality. Participants were allowed to complete the survey only once and exit it at any time, but if exited without clicking the 'submit' button their responses were not saved. They were required to complete the entire survey in a single session which lasted for approximately $8-10 \mathrm{~min}$. All the questions needed a response before the 'submit' button could be enabled. Where participants were not able to complete the survey 
themselves (for example, due to being computer illiterate), responses were either collected via telephone interviews by a member of the research team in local language or participants could ask their literate family members to complete the survey on their behalf. No face-to-face data collection was performed to avoid the risk of COVID-19 infection or transmission.

All survey responses were anonymous. Participant's responses across questions could vary from 'yes', 'no, 'not sure,' 'not applicable,' 'prefer not to say' etc. The responses were relabelled afterwards into binary forms, e.g., 'yes', 'no/not sure'. Responses like 'not applicable' (for example to a specific question, 'did you have to self-isolate because you tested positive for COVID-19 or had COVID-19 like symptoms?') were not included in the analyses. Guidelines for conducting survey studies were followed [32].

Exposure and outcome variables were categorised as per the aims of our study and analyses were carried out appropriately. Associations between exposure variables (age, gender, duration of diabetes and type of treatment, known complications of diabetes, and the need for mandatory self-isolation) and each outcome variable (fluctuation of blood glucose levels, change in access to diabetes medicine and healthy diet, and change in physical activity) was examined.

\section{Data analysis}

Bivariate analysis (Chi-square, Fisher's exact test) examined associations between each exposure and the outcome variable. Significant variables were then fitted into a multivariate logistic regression. Test of multicollinearity was performed for categorical variables, and where the exposure variables were highly correlated (e.g., need to self-isolate, testing positive for COVID-19) only one variable was used in the multivariate logistic regression analysis.

\section{Results}

Out of all the 679 participants, as Table 1 shows, 52\% were males, over $61 \%$ were $\geq 50$ years of age, $57 \%$ reported having diabetes for more than 5 years and $8.6 \%$ reported they had developed at least one form of longterm complications of diabetes such as the retinopathy. Of the total, $30.4 \%$ were on insulin treatment, $20.6 \%$ $(n=140)$ needed to self-isolate because of the COVID-19 infection in themselves or someone living with or experiencing COVID-19 like symptoms such as fever, persistent cough, difficulty breathing and loss of taste and smell. COVID-19 symptoms lasted for more than one week in $62.1 \%$ of those who needed to self-isolate.

Rest of the 'Results' focus on identifying factors that were associated with different outcomes important for diabetes self-management (A-D, below) during (specific to) the COVID-19 pandemic compared to pre-pandemic.

\section{Greater fluctuation of blood glucose levels}

A total of 242 (35.6\%) participants reported that their blood glucose levels fluctuated more during the COVID pandemic compared to the pre-pandemic. Table 2A shows Chi-square results for various exposure variables associated with the greater fluctuation of blood glucose levels during the pandemic.

Multivariate logistic regression showed a greater fluctuation in blood glucose levels was significantly associated with the need to self-isolate $(O R=1.8,95 \%$ $C I=1.2-2.6, p=0.005$ ) (Table 2B) and also with the presence of at least one form of long-term complication of diabetes such as the retinopathy, neuropathy and nephropathy $(O R=2.2,95 \% C I=1.2-3.9, p=0.008)$.

\section{Reduced access to diabetes medicine}

A total of 94 (13.8\%) participants reported their access to diabetes medicine got worse during the pandemic compared to the pre-pandemic. Table 3A shows Chi-square results for various exposure variables associated with reduced access to diabetes medicine during the pandemic (compared to pre-pandemic).

Multivariate logistic regression showed reduced access to diabetes medicine was significantly associated with the need to self-isolate $(O R=1.9,95 \% C I=1.1-3.1, p=0.02)$ (Table $3 \mathrm{~B})$ and the use of insulin treatment $(O R=2.1$, 95\% $C I=1.3-3.3, p=0.001$ ).

\section{Reduced access to right kind of food}

A total of $142(20.9 \%)$ participants reported that their access to the right kind of food suggested for good diabetes control reduced during the pandemic compared to pre-pandemic. Table 4A shows Chi-square results for various exposure variables associated with the reduced access to healthy food recommended for good diabetes control during the pandemic (compared to pre-pandemic).

Multivariate logistic regression showed that reduced access to healthy food recommended for good diabetes control was significantly associated with the need to selfisolate $(O R=3.0,95 \% C I=2.0-4.6, p<0.001)$ (Table 4B).

\section{Reduced physical activity}

A total of 308 (45.4\%) participants reported that their overall physical activity reduced during the pandemic compared to pre-pandemic. Table 5 shows Chi-square results for various exposure variables associated with reduced physical activity during the pandemic (compared to pre-pandemic). None of the exposure variables 
Table 2 Fluctuation of blood glucose levels

\begin{tabular}{|c|c|c|c|c|}
\hline \multirow[b]{2}{*}{ Exposure variable } & \multirow[b]{2}{*}{ Exposure variable response category } & \multicolumn{2}{|c|}{$\begin{array}{l}\text { Outcome variable (Greater fluctuation of blood } \\
\text { sugar levels) response category }\end{array}$} & \multirow[t]{2}{*}{ P-value } \\
\hline & & Yes & No/not sure & \\
\hline \multirow[t]{2}{*}{ Age group } & $<50$ years & 105 (38.9\%) & $165(61.1 \%)$ & \multirow[t]{2}{*}{0.93} \\
\hline & 50 years or above & $137(38.3 \%)$ & $221(61.7 \%)$ & \\
\hline \multirow[t]{2}{*}{ Gender } & Male & $126(38.9 \%)$ & $198(61.1 \%)$ & \multirow[t]{2}{*}{0.87} \\
\hline & Female & $116(38.2 \%)$ & $188(61.8 \%)$ & \\
\hline \multirow[t]{2}{*}{ Duration of diabetes } & Up to 5 years & 105 (38.9\%) & $165(61.1 \%)$ & \multirow[t]{2}{*}{0.47} \\
\hline & $>5$ years & $137(38.3 \%)$ & $221(61.7 \%)$ & \\
\hline \multirow[t]{2}{*}{ Treatment of diabetes } & Non-insulin & $161(36.6 \%)$ & $279(63.4 \%)$ & \multirow[t]{2}{*}{0.07} \\
\hline & Insulin/combined & $80(43.5 \%)$ & $105(56.5 \%)$ & \\
\hline \multirow{2}{*}{$\begin{array}{l}\text { Presence of diabetes complications like } \\
\text { retinopathy }\end{array}$} & Yes & $30(56.6 \%)$ & $23(43.4 \%)$ & \multirow[t]{2}{*}{$0.005^{*}$} \\
\hline & No/not sure & $189(36.9 \%)$ & $323(63.1 \%)$ & \\
\hline \multirow[t]{2}{*}{ Needing self-isolation } & Yes & $65(50.0 \%)$ & $65(50.0 \%)$ & \multirow[t]{2}{*}{$0.003^{*}$} \\
\hline & No/prefer not say & $177(35.5 \%)$ & $321(64.5 \%)$ & \\
\hline \multirow[t]{2}{*}{ Duration of self-isolation } & Up to one week & $26(48.1 \%)$ & $25(51.9 \%)$ & \multirow[t]{2}{*}{0.44} \\
\hline & More than one week & $38(48.1 \%)$ & $41(51.9 \%)$ & \\
\hline \multicolumn{5}{|l|}{ B } \\
\hline \multirow[t]{2}{*}{ Exposure variable } & \multirow[t]{2}{*}{ Exposure variable category } & $\begin{array}{l}\text { Association } \\
\text { sugar levels }\end{array}$ & fluctuation of blood & \multirow[t]{2}{*}{ P-value } \\
\hline & & Odds Ratio & & \\
\hline \multirow{2}{*}{$\begin{array}{l}\text { Presence of diabetes complications like } \\
\text { retinopathy }\end{array}$} & Yes & 2.18 & $(1.23-3.87)$ & \multirow[t]{2}{*}{$0.008^{*}$} \\
\hline & No/not sure (Reference) & & & \\
\hline \multirow[t]{2}{*}{ Needing to self-isolate } & Yes & 1.76 & $(1.18-2.61)$ & \multirow[t]{2}{*}{$0.005^{*}$} \\
\hline & No/prefer not say (Reference) & & & \\
\hline
\end{tabular}

A Chi-square tests showing association of various exposure variables with the outcome variable of greater fluctuation of blood glucose levels during the pandemic compared to pre-pandemic. *represent significant p-values. B Adjusted Multivariate Logistic Regression results showing needing to self-isolate and presence of diabetes complications as significant factors associated with greater fluctuation of blood glucose levels during the pandemic compared to pre-pandemic

was found to be significantly associated with the outcome variable of reduced physical activity.

The outcome variables provided in Table 2 (fluctuation in blood sugar levels) and Table 3 (access to diabetic medicine) are not strictly the self-care behaviors. Nonetheless, the inclusion of these variables respectively provided reflection of whether diabetes was adequately monitored and controlled, and the patients' compliance with diabetes medication, which are important self-care behaviors [33].

\section{Discussion and conclusion}

Diabetes is one of the most commonly reported comorbidities in people infected with COVID-19 [34-36]. At a time when access to health care facilities is severely limited owing to lockdown/quarantine measures and cancellation or postponement of routine/non-urgent appointments, it has become more important than ever before to examine how various factors influence diabetes self-management during the COVID-19 pandemic. Limited access to medicine and healthcare professionals, fresh food, physical activity, and increased stress and anxiety have been identified as common barriers to good diabetic control during the COVID pandemic $[15,25-28$, 37]. In this study, we extend and show how other factors including the need to self-isolate, duration of self-isolation, age, gender, duration, treatment and complications of diabetes are associated with diabetes self-management during the COVID pandemic so that specific barriers to improved diabetes self-management can be targeted.

The prevalence of COVID-19 infection (confirmed by a standard PCR test) was found to be $8.1 \%$ in all our participants agreeing with previous studies which have reported rates of $8-10 \%$ in people with diabetes in the community [38, 39]. However, among patients hospitalized with COVID-19, a much higher prevalence (19\%) of diabetes has been reported [40]. 
Table 3 Reduced access to diabetes medicine

\begin{tabular}{|c|c|c|c|c|}
\hline \multicolumn{5}{|l|}{$A$} \\
\hline \multirow[b]{2}{*}{ Exposure variable } & \multirow[b]{2}{*}{ Exposure variable category } & \multicolumn{2}{|c|}{$\begin{array}{l}\text { Outcome variable (Reduced access to diabetes } \\
\text { medicine) response category }\end{array}$} & \multirow[t]{2}{*}{ P-value } \\
\hline & & Yes & No/not sure & \\
\hline \multirow[t]{2}{*}{ Age group } & $<50$ years & $35(17.2 \%)$ & $168(82.8 \%)$ & \multirow[t]{2}{*}{0.99} \\
\hline & 50 years or above & $59(17.4 \%)$ & $281(82.6 \%)$ & \\
\hline \multirow[t]{2}{*}{ Gender } & Male & $48(16.8 \%)$ & $237(83.2 \%)$ & \multirow[t]{2}{*}{0.82} \\
\hline & Female & $46(17.8 \%)$ & $212(82.2 \%)$ & \\
\hline \multirow[t]{2}{*}{ Duration of diabetes } & Up to 5 years & $36(17.0 \%)$ & $176(83.0 \%)$ & \multirow[t]{2}{*}{0.91} \\
\hline & $>5$ years & $58(17.5 \%)$ & $273(82.5 \%)$ & \\
\hline \multirow[t]{2}{*}{ Treatment of diabetes } & Non-insulin & $48(13.4 \%)$ & $310(86.6 \%)$ & \multirow[t]{2}{*}{$0.001^{*}$} \\
\hline & Insulin/combined & $46(25.0 \%)$ & $138(75.0 \%)$ & \\
\hline \multirow{2}{*}{$\begin{array}{l}\text { Presence of diabetes complications like } \\
\text { retinopathy }\end{array}$} & Yes & $14(26.9 \%)$ & $38(73.1 \%)$ & \multirow[t]{2}{*}{0.08} \\
\hline & No/not sure & $79(16.2 \%)$ & $409(83.8 \%)$ & \\
\hline \multirow[t]{2}{*}{ Needing to self-isolate } & Yes & $28(25.5 \%)$ & $82(74.5 \%)$ & \multirow[t]{2}{*}{$0.02^{*}$} \\
\hline & No/prefer not say & $66(15.2 \%)$ & $367(84.8 \%)$ & \\
\hline \multirow[t]{2}{*}{ Duration of self-isolation } & Up to 1 week & $8(21.1 \%)$ & $30(78.9 \%)$ & \multirow[t]{2}{*}{0.64} \\
\hline & More than 1 week & $19(26.0 \%)$ & $54(74.0 \%)$ & \\
\hline \multicolumn{5}{|l|}{$\underline{B}$} \\
\hline \multirow[t]{2}{*}{ Exposure variable } & \multirow[t]{2}{*}{ Exposure variable category } & $\begin{array}{l}\text { Associatio } \\
\text { medicine }\end{array}$ & d access to diabetes & \multirow[t]{2}{*}{ P-value } \\
\hline & & Odds Ratio & & \\
\hline \multirow[t]{2}{*}{ Treatment of diabetes } & Insulin or combined & 2.13 & $(1.35-3.35)$ & $0.001^{*}$ \\
\hline & Non-insulin (Reference) & & & \\
\hline \multirow[t]{2}{*}{ Needing to self-isolate } & Yes & 1.86 & $(1.11-3.09)$ & \multirow[t]{2}{*}{$0.02^{*}$} \\
\hline & No/prefer not say (Reference) & & & \\
\hline
\end{tabular}

A Chi-square results showing association of various exposure variables with the outcome variable of reduced access to diabetes medicine during the pandemic compared to pre-pandemic. *represent significant p-values. B Adjusted Multivariate Logistic Regression results showing needing to self-isolate and being on insulin treatment are associated significantly with reduced access to diabetes medicine during the pandemic compared to pre-pandemic

In our total sample, $35.6 \%$ reported that their blood glucose levels fluctuated more during the pandemic. In addition, $45.4 \%$ of participants reported their physical activity reduced during the pandemic. A study from India in young adults with type 1 diabetes reported deterioration of blood glucose levels in $72 \%$ of people and reduced physical activity in $90 \%$ of people during the pandemic [41]. Our study agrees with that of Khare and Jindal [26], who reported worsening of blood glucose level in 39.2\% of diabetes patients although it was not clear what proportion of these patients were self-isolating.

Needing to self-isolate was found to be the single most important factor influencing all (but reduced physical activity) variables investigated in our study that have the potential to influence diabetes self-management. The likelihood of fluctuation in blood glucose levels was nearly two times higher $(O R=1.8,95 \%, p=0.005$, $C I=1.2-2.6)$ in those who needed to self-isolate compared to those who did not need to self-isolate, and over two times higher $(O R=2.2,95 \%, p=0.008, C I=1.2-3.9)$ in those who had diabetes complications compared to those who did not.

Self-isolation was significantly associated with reduced access to diabetes medicine during the pandemic with odds ratio of nearly two times higher $(O R=1.9,95 \%$, $p=0.02, C I=1.1-3.1)$ in those who needed to self-isolate compared to those who did not. In addition, those who were on insulin treatment were over two times more likely to have reduced access to diabetes medicine $(\mathrm{OR}=2.1,95 \%, p=0.001, C I=1.3-3.3)$ compared to those who were not on insulin treatment.

Our study adds to the literature in that we show that self-isolation was also significantly associated with reduced access to healthy food and diabetes medicine. A qualitative study from Wuhan, China in patients with Type 2 diabetes $(n=12)$ who had to self-isolate after being discharged from the hospital for COVID infection identified barriers such as shortage of physical spaces and resources (food, medicine) to be the key factors hindering diabetes self-management [25]. 
Table 4 Reduced access to healthy diet recommended for good diabetes control

\begin{tabular}{|c|c|c|c|c|}
\hline \multicolumn{5}{|l|}{$A$} \\
\hline \multirow[b]{2}{*}{ Exposure variable } & \multirow[b]{2}{*}{ Exposure variable category } & \multicolumn{2}{|c|}{$\begin{array}{l}\text { Outcome variable (Reduced access to healthy } \\
\text { diet) response category }\end{array}$} & \multirow[t]{2}{*}{ P-value } \\
\hline & & Yes & No/not sure & \\
\hline \multirow[t]{2}{*}{ Age group } & $<50$ years & $54(21.8 \%)$ & $194(78.2 \%)$ & \multirow[t]{2}{*}{0.77} \\
\hline & 50 years or above & 88 (22.9\%) & $297(77.1 \%)$ & \\
\hline \multirow[t]{2}{*}{ Gender } & Male & $68(20.7 \%)$ & $261(79.3 \%)$ & \multirow[t]{2}{*}{0.29} \\
\hline & Female & $74(24.3 \%)$ & $230(75.7 \%)$ & \\
\hline \multirow[t]{2}{*}{ Duration of diabetes } & Up to 5 years & $70(26.0 \%)$ & 199 (74.0\%) & \multirow[t]{2}{*}{$0.06^{*}$} \\
\hline & $>5$ years & $72(19.8 \%)$ & $292(80.2 \%)$ & \\
\hline \multirow[t]{2}{*}{ Treatment of diabetes } & Non-insulin & $96(21.7 \%)$ & $346(78.3 \%)$ & \multirow[t]{2}{*}{0.53} \\
\hline & Insulin/combined & $45(24.2 \%)$ & $141(75.8 \%)$ & \\
\hline \multirow{2}{*}{$\begin{array}{l}\text { Presence of diabetes complications like } \\
\text { retinopathy }\end{array}$} & Yes & $13(24.5 \%)$ & $40(75.5 \%)$ & \multirow[t]{2}{*}{0.73} \\
\hline & No/not sure & $128(22.2 \%)$ & $448(77.8 \%)$ & \\
\hline \multirow[t]{2}{*}{ Needing to self-isolate } & Yes & $50(52.0 \%)$ & 75 (48.0\%) & \multirow[t]{2}{*}{$<0.001^{*}$} \\
\hline & No/prefer not say & $92(23.4 \%)$ & $146(76.6 \%)$ & \\
\hline \multirow[t]{2}{*}{ Duration of self-isolation } & Up to one week & $25(53.2 \%)$ & $22(46.8 \%)$ & \multirow[t]{2}{*}{0.57} \\
\hline & More than one week & $33(42.9 \%)$ & $44(57.1 \%)$ & \\
\hline \multicolumn{5}{|l|}{ B } \\
\hline \multirow[t]{2}{*}{ Exposure variable } & \multirow[t]{2}{*}{ Exposure variable category } & Association & d access to healthy diet & \multirow[t]{2}{*}{ P-value } \\
\hline & & Odds Ratio & & \\
\hline \multirow[t]{2}{*}{ Duration of diabetes } & Up to 5 years & 1.01 & $(0.68-1.50)$ & \multirow[t]{2}{*}{0.6} \\
\hline & $>5$ years (Reference) & & & \\
\hline \multirow[t]{2}{*}{ Needing to self-isolate } & Yes & 3.01 & $(1.97-4.60)$ & \multirow[t]{2}{*}{$<0.001^{*}$} \\
\hline & No/prefer not say (Reference) & & & \\
\hline
\end{tabular}

A Chi-square results showing association of various exposure variables with the outcome variable of reduced access to healthy food for good diabetic control during the pandemic compared to pre-pandemic. *represent significant (or near significant) p-values. B Adjusted Multivariate Logistic Regression results showing needing to self-isolate is associated significantly with reduced access to healthy food during the pandemic compared to pre-pandemic

It was somewhat surprising that none of the exposure variables, and in particular those who needed selfisolation, were found to be significantly associated with reduced physical activity during the COVID-19 pandemic. This may be because living either under total or partial lockdown at the time of the survey could have limited the overall outdoor physical activities for most participants and not just for those who needed to selfisolate [18, 27].

Self-management of diabetes involves many more activities (foot care, smoking, adherence to medications, stress management, keeping review dates, etc.) in addition to the parameters we have examined. Inclusion of those parameters would have made the study more comprehensive and can be included in a future study. Also, our study compared self-reported data before and during the pandemic. This retrospective judgement could have been influenced by differences in bias and memory recall abilities. However, the only way around that would have been to collect the data before the pandemic began which was not possible.

While some earlier studies have reported the positive effect of COVID pandemic on behavior of diabetes people such as increased consumption of fruits and vegetables [23] and increased motivation for home exercise [42], several other studies have shown that access to healthy diet and physical exercises in diabetes people deteriorated significantly during the COVID19 pandemic [15-18]. Our data show that people with diabetes who are required to self-isolate are at a higher odds of poor diabetes self-management (as a result of reduced access to healthy food and diabetes medicine) and uncontrolled diabetes, and need more informed self-management guidelines in order to enable better self-management. In addition, our data also show the need for having improved access to diabetes medicine in those who are on insulin treatment, and increased awareness about self-monitoring of glucose levels in 
Table 5 Reduced physical activity

\begin{tabular}{|c|c|c|c|c|}
\hline \multirow[b]{2}{*}{ Exposure variable } & \multirow[b]{2}{*}{ Exposure variable category } & \multicolumn{2}{|c|}{$\begin{array}{l}\text { Outcome variable (reduced physical activitiy) } \\
\text { response category }\end{array}$} & \multirow[b]{2}{*}{ P-value } \\
\hline & & Yes & No/not sure & \\
\hline \multirow[t]{2}{*}{ Age group } & $<50$ years & $118(47.6 \%)$ & $130(52.4 \%)$ & \multirow[t]{2}{*}{0.41} \\
\hline & 50 years or above & $190(51.1 \%)$ & $182(49.9 \%)$ & \\
\hline \multirow[t]{2}{*}{ Gender } & Male & $150(46.9 \%)$ & $170(53.1 \%)$ & \multirow[t]{2}{*}{0.17} \\
\hline & Female & $158(52.7 \%)$ & $142(47.3 \%)$ & \\
\hline \multirow[t]{2}{*}{ Duration of diabetes } & Up to 5 years & 135 (49.8\%) & $136(50.2 \%)$ & \multirow[t]{2}{*}{0.99} \\
\hline & $>5$ years & $173(49.6 \%)$ & $176(50.4 \%)$ & \\
\hline \multirow[t]{2}{*}{ Treatment of diabetes } & Non-insulin & $217(49.8 \%)$ & $219(50.2 \%)$ & \multirow[t]{2}{*}{0.99} \\
\hline & Insulin/combined & $90(50.0 \%)$ & $90(50.0 \%)$ & \\
\hline \multirow{2}{*}{$\begin{array}{l}\text { Presence of diabetes complications like } \\
\text { retinopathy }\end{array}$} & Yes & $26(55.3 \%)$ & $21(44.7 \%)$ & \multirow[t]{2}{*}{0.45} \\
\hline & No/not sure & $280(49.2 \%)$ & $289(50.8 \%)$ & \\
\hline \multirow[t]{2}{*}{ Needing to self-isolate } & Yes & $66(51.2 \%)$ & $63(48.8 \%)$ & \multirow[t]{2}{*}{0.77} \\
\hline & No/prefer not say & $242(49.3 \%)$ & $249(50.7 \%)$ & \\
\hline \multirow[t]{2}{*}{ Duration of self-isolation } & Up to one week & $20(41.7 \%)$ & $28(58.3 \%)$ & \multirow[t]{2}{*}{0.14} \\
\hline & More than one week & $45(56.2 \%)$ & $35(43.8 \%)$ & \\
\hline
\end{tabular}

Chi-square results showing association of various exposure variables with the outcome variable of reduced physical activity during the pandemic compared to prepandemic. Multivariate Regression analysis was not performed since significant association was found for none of the exposure variable

people who have complications of diabetes in order to prevent further serious complications. Public health policies should give priority to those people with diabetes who need to isolate because of COVID-19 infection and also those who have diabetes complications in order to ensure that they are able to manage their diabetes appropriately during the pandemic.

\section{Acknowledgements}

Authors would like to thank all volunteers who participated in the study.

\section{Authors' contributions}

SP and RS drafted the manuscript. MSI, GFL, TLU revised the manuscript. All authors contributed to the article and approved the submitted version. All authors read and approved the final manuscript.

\section{Funding}

The author (s) received no financial support for the research, authorship, and/ or publication of this article.

\section{Availability of data and materials}

The datasets generated during and/or analysed during the current study are available from the corresponding author on reasonable request.

\section{Declarations}

Ethics approval and consent to participate

The study protocol was approved by Anglia Ruskin University's Faculty of Health, Education, Medicine and Social Care Research Ethics Panel [ref. no.: 19/20/024].

\section{Consent for publication}

Not applicable.

\section{Competing interests}

The authors declare that they have no competing interests.

\section{Author details}

${ }^{1}$ Vision and Eye Research Institute, School of Medicine, Anglia Ruskin University, East Road, Cambridge CB1 1PT, UK. ${ }^{2}$ Department of Public Health and Informatics, Jahangirnagar University, Savar Dhaka-1342, Bangladesh.

${ }^{3}$ Department of Medicine, Gandaki Medical College and Teaching Hospital, Pokhara, Nepal.

Received: 2 July 2021 Accepted: 11 October 2021

Published online: 29 October 2021

\section{References}

1. World Health Organisation Coronavirus Disease (COVID-19) Dashboard. https://covid19.who.intAccessed 1 Jun 2021.

2. Fisher L, Polonsky W, Asuni A, Jolly Y, Hessler D. The early impact of the COVID-19 pandemic on adults with type 1 or type 2 diabetes: A national cohort study. J Diabetes Complications. 2020;34(12):107748.

3. Asif $\mathrm{M}$. The prevention and control the type-2 diabetes by changing lifestyle and dietary pattern. J Educ Health Promot. 2014;3:1.

4. Franz MJ, Bantle JP, Beebe CA, Brunzell JD, Chiasson J, Garg A, et al. Evidence-based nutrition principles and recommendations for the treatment and prevention of diabetes and related complications. Diabetes Care. 2002;25(1):148-98.

5. Campbell HM, Khan N, Cone C, Raisch DW. Relationship between diet, exercise habits, and health status among patients with diabetes. Res Social Adm Pharm. 2011;7(2):151-61.

6. Muliyil DE, Vellaiputhiyavan K, Alex R, Mohan VR. Compliance to treatment among type 2 diabetics receiving care at peripheral mobile clinics in a rural block of Vellore District, Southern India. J Family Med Prim Care. 2017:6(2):330-5.

7. Karter AJ, Parker MM, Moffet HH, Ahmed AT, Ferrara A, Liu JY, et al. Missed appointments and poor glycemic control: an opportunity to identify high-risk diabetic patients. Med Care. 2004;42(2):110-5.

8. Sapkota R, Chen Z, Zheng D, Pardhan S. The profile of sight-threatening diabetic retinopathy in patients attending a specialist eye clinic in Hangzhou, China. BMJ Open Ophthalmol. 2019;4(1):e000236. 
9. Sapkota RP, Upadhyaya T, Gurung G, Parker M, Raman R, Pardhan S. Need to improve awareness and treatment compliance in high-risk patients for diabetic complications in Nepal. BMJ Open Diabetes Res Care. 2018;6(1):e000525.

10. Kumar A, Arora A, Sharma P, Anikhindi SA, Bansal N, Singla V, et al. Is diabetes mellitus associated with mortality and severity of COVID-19? A meta-analysis Diabetes Metab Syndr. 2020;14(4):535-45.

11. Barriers and facilitators for type-2 diabetes management in south asians: a systematic review. PLoS One 2015;10 (9):e0136202.

12. Gaede $P$, Vedel $P$, Parving HH, Pedersen O. Intensified multifactorial intervention in patients with type 2 diabetes mellitus and microalbuminuria: the Steno type 2 randomised study. Lancet. 1999;353(9153):617-22.

13. Macisaac RJ, Jerums G. Intensive glucose control and cardiovascular outcomes in type 2 diabetes. Heart Lung Circ. 2011;20(10):647-54.

14. Diabetes UK. Improving supported self-management for people with diabetes. 2009.https://www.diabetes.org.uk/resources-s3/2017-09/Suppo rted_self-management.pdf. Accessed 1 June 2021

15. Ghosh A, Arora B, Gupta R, Anoop S, Misra A. Effects of nationwide lockdown during COVID-19 epidemic on lifestyle and other medical issues of patients with type 2 diabetes in north India. Diabetes Metab Syndr. 2020;14(5):917-20.

16. Ruiz-Roso MB, Knott-Torcal C, Matilla-Escalante DC, Garcimartín A, Sampedro-Nuñez MA, Dávalos A, et al. COVID-19 lockdown and changes of the dietary pattern and physical activity habits in a cohort of patients with type 2 diabetes mellitus. Nutrients. 2020. https://doi.org/10.3390/ nu12082327.

17. Marçal IR, Fernandes B, Viana AA, Ciolac EG. The urgent need for recommending physical activity for the management of diabetes during and beyond COVID-19 outbreak. Front Endocrinol (Lausanne). 2020;11:584642.

18. Assaloni R, Pellino VC, Puci MV, Ferraro OE, Lovecchio N, Girelli A, et al. Coronavirus disease (Covid-19): How does the exercise practice in active people with type 1 diabetes change? A preliminary survey. Diabetes Res Clin Pract. 2020;166:108297.

19. Alessi J, De Oliveira GB, Franco DW, Do Amaral BB, Becker AS, Knijnik CP, et al. Mental health in the era of COVID-19: prevalence of psychiatric disorders in a cohort of patients with type 1 and type 2 diabetes during the social distancing. Diabetol Metab Syndr. 2020. https://doi.org/10.1186/ s13098-020-00584-6.

20. Xue T, Li Q, Zhang Q, Lin W, Wen J, Li L, et al. Blood glucose levels in elderly subjects with type 2 diabetes during COVID-19 outbreak: a retrospective study in a single center 2020. Endocrinology. 2020. https://doi. org/10.1101/2020.03.31.20048579.

21. Ghosal S, Sinha B, Majumder M, Misra A. Estimation of effects of nationwide lockdown for containing coronavirus infection on worsening of glycosylated haemoglobin and increase in diabetes-related complications: a simulation model using multivariate regression analysis. Diabetes Metab Syndr. 2020;14(4):319-23.

22. Ghosh A, Anjana RM, Shanthi Rani CS, Jeba Rani S, Gupta R, Jha A, et al. Glycemic parameters in patients with new-onset diabetes during COVID19 pandemic are more severe than in patients with new-onset diabetes before the pandemic: NOD COVID India Study. Diabetes Metab Syndr. 2021. https://doi.org/10.1016/j.ds×2020.12.033.

23. Grabia M, Markiewicz-Żukowska R, Puścion-Jakubik A, Bielecka J, Nowakowski P, Gromkowska-Keppka K, et al. The nutritional and health effects of the COVID-19 pandemic on patients with diabetes mellitus. Nutrients. 2020. https://doi.org/10.3390/nu12103013.

24. Bonora BM, Boscari F, Avogaro A, Bruttomesso D, Fadini GP. Glycaemic control among people with type 1 diabetes during lockdown for the SARS-CoV-2 outbreak in Italy. Diabetes Ther. 2020;11:1-11.

25. Shi C, Zhu H, Liu J, Zhou J, Tang W. Barriers to self-management of type 2 diabetes during COVID-19 medical isolation: a qualitative study. Diabetes Metab Syndr Obes. 2020;13:3713-25.
26. Khare J, Jindal S. Observational study on effect of lock down due to COVID 19 on glycemic control in patients with diabetes: experience from central india. Diabetes Metab Syndr. 2020;14(6):1571-4.

27. Kishimoto M, Ishikawa T, Odawara M. Behavioral changes in patients with diabetes during the COVID-19 pandemic. Diabetol Int. 2020;12(2):1-5.

28. Potier L, Hansel B, Larger E, Gautier JF, Carreira D, Assemien R, et al. Stay-at-home orders during the COVID-19 pandemic, an opportunity to improve glucose control through behavioral changes in type 1 diabetes. Diabetes Care. 2021:44(3):839-43.

29. Schmitt A, Gahr A, Hermanns N, Kulzer B, Huber J, HaakT. The Diabetes Self-Management Questionnaire (DSMQ): development and evaluation of an instrument to assess diabetes self-care activities associated with glycaemic control. Health Qual Life Outcomes. 2013;11:138.

30. Pardhan S, Nakafero G, Raman R, Sapkota R. Barriers to diabetes awareness and self-help are influenced by people's demographics: perspectives of South Asians with type 2 diabetes. Ethn Health. 2020;25:843-61.

31. Saquib N, Saquib J, Ahmed T, Khanam MA, Cullen MR. Cardiovascular diseases and type 2 diabetes in Bangladesh: a systematic review and meta-analysis of studies between 1995 and 2010. BMC Public Health. 2012:12:434.

32. Kelley K, Clark B, Brown V, Sitzia J. Good practice in the conduct and reporting of survey research. Int J Qual Health Care. 2003;15:261-6.

33. American Association of Diabetes Educators. An effective model of diabetes care and education: revising the AADE7 self-care behaviors. Diabetes Educ. 2020;46(2):139-60.

34. Li B, Yang J, Zhao F, Zhi L, Wang X, Liu L, et al. Prevalence and impact of cardiovascular metabolic diseases on COVID-19 in China. Clin Res Cardiol. 2020;109(5):531-8.

35. Hu Y, Sun J, Dai Z, Deng H, Li X, Huang Q, et al. Prevalence and severity of corona virus disease 2019 (COVID-19): a systematic review and metaanalysis. J Clin Virol. 2020:127:104371.

36. Rodriguez-Morales AJ, Cardona-Ospina JA, Gutiérrez-Ocampo E, Villamizar-Peña R, Holguin-Rivera Y, Escalera-Antezana JP, et al. Clinical, laboratory and imaging features of COVID-19: a systematic review and meta-analysis. Travel Med Infect Dis. 2020;34:101623.

37. Khader MA, Jabeen T, Namoju R. A cross sectional study reveals severe disruption in glycemic control in people with diabetes during and after lockdown in India. Diabetes Metab Syndr. 2020;14(6):1579-84.

38. Fadini GP, Morieri ML, Longato E, Avogaro A. Prevalence and impact of diabetes among people infected with SARS-CoV-2. J Endocrinol Invest. 2020;43(6):867-9.

39. Huang I, Lim MA, Pranata R. Diabetes mellitus is associated with increased mortality and severity of disease in COVID-19 pneumonia-a systematic review, meta-analysis, and meta-regression. Diabetes Metab Syndr. 2020;14(4):395-403.

40. Docherty AB, Harrison EM, Green CA, Hardwick H, Pius R, Norman L, et al. Features of 16,749 hospitalised UK patients with COVID-19 using the ISARIC WHO clinical characterisation protocol. medRxiv preprint. 2020. https://doi.org/10.1101/2020.04.23.20076042.

41. Pal R, Yadav U, Verma A, Bhadada SK. Awareness regarding COVID-19 and problems being faced by young adults with type 1 diabetes mellitus amid nationwide lockdown in India: A qualitative interview study. Prim Care Diabetes. 2021;15(1):10-5.

42. Kaur H, Singh T, Arya YK, Mittal S. Physical fitness and exercise during the COVID-19 pandemic: a qualitative enquiry. Front Psychol. 2020;11:590172.

\section{Publisher's Note}

Springer Nature remains neutral with regard to jurisdictional claims in published maps and institutional affiliations. 